\title{
In conversation with John Gunn
}

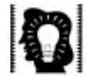

special articles

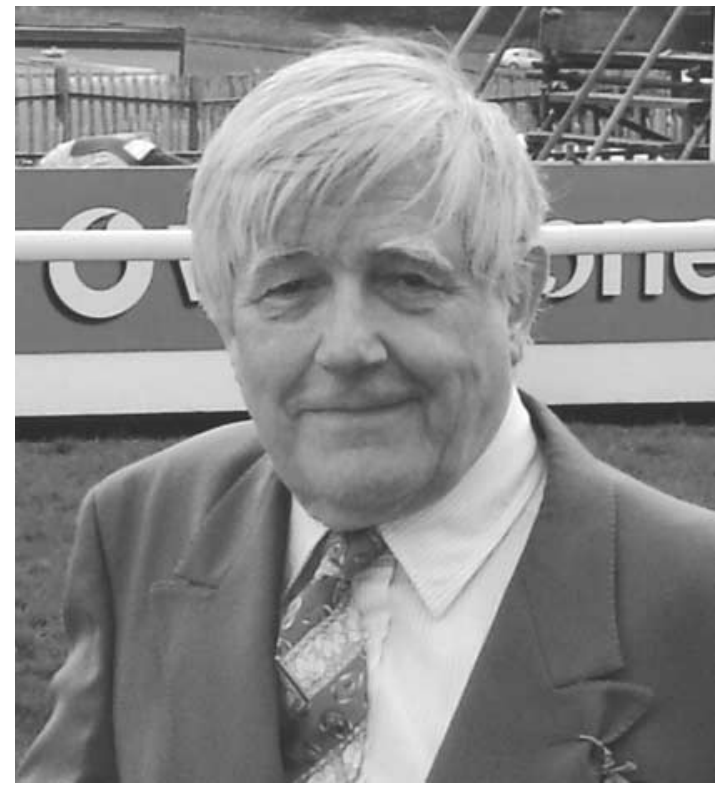

John Gunn CBE retired as Professor of Forensic Psychiatry at the Institute of Psychiatry, London in 2002. In February 2003 he agreed to an unrehearsed interview at the Annual Meeting of the Forensic Psychiatry Faculty in Glasgow. He was interviewed by Adrian Grounds.

\section{John, what led you into psychiatry first of all?}

It probably started when I was secretary of the science society at my grammar school and a boy wanted to discuss the works of Freud which he had just excitedly found. I thought this would be all right, although I didn't even know who Freud was. So we arranged this. The routine at the school was that the headmaster would read out the notices each day for the forthcoming events of the various societies. When he got to mine, I could see that he just turned it over. After the school assembly I was summoned to the headmaster's study to be given a lecture on the horrors of Freud. I was incensed by this.

We weren't allowed to run that session, but I went down to the local library and as you might imagine, we were all reading Freud for the next week or two in our school. So I think it goes back that far. However, there were all sorts of other influences at school, including Tinbergen and his ethological studies, which for me were absolutely seminal - I have always had an interest in ethology.

\section{What about forensic psychiatry?}

It started when I was first in the junior common room at the Maudsley. I was doing some moonlighting and a notice went up for a couple of people to do group sessions at a hostel for down-and-outs in Lambeth, with

\begin{abstract}
John Gunn trained in medicine at Birmingham University and went to the Maudsley Hospital in 1963. He became a research worker at the Institute of Psychiatry in 1967, wrote his MD on epilepsy in prisoners and became a senior lecturer in 1971. He was appointed Professor of Forensic Psychiatry in 1978 and built a thriving and influential department. His research output has included books on violence, psychiatric aspects of imprisonment and a major textbook of forensic psychiatry. His research has included major epidemiological studies in prisons, work in relation to the high-security hospitals, studies with Pamela Taylor on violence and psychosis, police-based studies of people with mental illness in custody, and collaborative studies with the Cambridge Longitudinal Study of Delinquency and with the MacArthur Programme. He led the development of secure provision in the South EastThames region, he was Clinical Director of the forensic services in his trust, Director of the Special Hospitals Research Unit, and contributed to the development of more recent services such as the Maudsley Traumatic Stress Clinic. Throughout he has always maintained his own clinical case-load and out-patient service. His public service contributions included 9 years on the Aarvold Board, he was psychiatric advisor to the Army and the Metropolitan Police, and in 1991 he was appointed as a member of the Royal Commission on Criminal Justice. He has chaired the academic board at the Institute of Psychiatry, and has made huge contributions in developing forensic psychiatry training in Britain and internationally. He was a founder editor of Criminal Behaviour and Mental Health. In the Royal College of Psychiatrists he was on the Court of Electors until June 2006, has chaired the Research Committee, was Deputy Chief Examiner and latterly was Chairman of the Forensic Psychiatry Faculty. As I heard a colleague remark today, for our specialty he is the chief architect of the space in which we work. Things would have been very different without him.
\end{abstract}

skid row alcoholics. So Gethin Morgan and I trundled off to meet Tim Cook who was an ex-prison governor running the project. I was absolutely fascinated by the work we were expected to do. Tim used to talk about prisons and I became captivated and asked to be allocated to the forensic psychiatry training at the Maudsley. However, there was always a reason why I couldn't be, and so I never did any forensic training as a senior house officer or registrar.

When I had finished my basic training I knew I wanted to do research and so I went around the Institute to see if there were any research posts going, and there weren't. At this time I came across Martin Roth who offered me a post in geriatric research in Newcastle. Coincidentally I had been editing the Festschrift for Aubrey Lewis who was retiring: the junior common room was editing two books of his collected papers for him and I was one of the three editors. He said, 'What do you want to go up there for, it's cold?' I said 'They have offered me a job'. 'Hmm, there must be a job here.' I told him I had been round and asked everybody, so he said 
(8)

special articles
'Have you spoken to Dr Gibbens', who was then Reader in Forensic Psychiatry. 'Yes I've done that', so he said 'Well, go and ask him again'. The next day in the canteen Trevor Gibbens came over to me and said 'It must have slipped my memory for I do have a post for you', so I was offered the research post and wrote my MD on epilepsy among prisoners (Gunn, 1977).

At that time epilepsy was the dangerous severe personality disorder (DSPD) of its day: the reason for violence in our society was that there was too much epilepsy, there was a brain dyscontrol syndrome, people had rage attacks, you could see it on the electroencephalogram (EEG). You didn't have to have risk assessment forms, it was better than that - you could actually see it on the EEG; and this was the future of control, the safety of our society and so on. The research was about trying to show what the real links were, if any, between crime and epilepsy.

You have a combative passion to improve the care of offenders: what it is that gives you a sense of sympathy for that group?

I empathise with people who have a bad time in life and I feel very angry and upset when people are ill-treated in any way, I always have, I don't know where it comes from, I think it's in my family; I just feel something should be done.

When you became a consultant in the early '70s you were the fourth consultant forensic psychiatrist in the country. Can you give a flavour of the state of forensic psychiatry at that time?

There wasn't really a specialty of forensic psychiatry at that time, but there were people doing forensic psychiatry, for example in the special hospitals. When I started there was just an ad hoc group of people, including Patrick McGrath, Trevor Gibbens, Peter Scott and others. We got together to form a section within the Royal Medico-Psychological Association and later the College. What was the main function of that section? It was to run an annual conference. The explosion in training came after the Butler Report (Home Office \& Department of Health and Social Security, 1975).

After the Butler Committee reported you became very involved in the development of the South East Thames forensic services. An interim medium secure unit opened in 1980 and the Denis Hill Unit in 1985. What did you learn about the task of developing services?

It was an extremely difficult time but it was a very interesting experience looking back on it. Denis Hill was on the Butler Committee. He ensured the development of forensic psychiatry at the Institute. He came back from the Butler Committee with the proposals for regional secure units. The proposals had been around a long time really, but the Butler Committee had focused them because of the overcrowding in the special hospitals. The interim report proposed that medium security units should be built in every region and this was accepted. 'We are going to do one here for South East Thames, it will be a big unit at the Bethlem' he said. I thought 'I hope you do, but let's see'. He went off to the medical committee to put his proposals and he had total rejection. 'We're not having those patients here' was the crie de coeur; there were 101 arguments against the proposal: it would take resources away from general psychiatry, it would change the nature of the Maudsley and Bethlem Hospital, etc, etc. Denis Hill was absolutely appalled and it took a long time to calm him down. But eventually he looked at me and said 'You do it'. I protested that I couldn't, but in the event I spent the next 2 years doing political deals. Eventually we could have a unit but it had to be a very small one. So we set up an interesting model of a central unit at Bethlem with smaller peripheral units throughout the region. It wasn't the model I would have chosen but it had the obvious attraction that the units could provide local services. The opposite model was developed by Robert Bluglass: a very large unit in an old Birmingham mental hospital site which became the Raeside Clinic. We took bets as to which would survive longer and he was clearly on to the winner because moderately large size is not a negative characteristic in hospital design but a positive one.

What do you think have been the effects of the prison research you have done? Your epidemiological studies were dramatic in their implications for what was needed in the National Health Service. What was their impact?

Very little. It's a harsh thing to say about one's own life and work, but to be honest I can't see that anything that has happened has really resulted from research that we or anybody else has done. I'm much more impressed that politics rather than research changes things. There can never be a reason for not doing research, I feel passionately about the importance and centrality of research, but ultimately the country is run on politics, not data or evidence as we are told it is. Nevertheless, I like to think we had some impact in preserving Grendon Underwood prison, because we did the first and the only controlled study of Grendon's effectiveness, and we showed its therapeutic community model worked.

What is your view of the history of the high secure hospitals in your time? Has there been any period of model management and care?

I think there has. They started in 1815 at Bethlem. There was a wing at Bethlem for criminal lunatics and that grew into Broadmoor Hospital. Dundrum was the first special hospital in the British Isles. The government in those days had the canny idea of trying things out in Ireland first! When the governors got fed up with the patients in Bethlem, Broadmoor was built at Crowthorne in 1863, and I think that together with Dundrum changed the British attitude to offender patients. People ask why British forensic psychiatry is different from other countries. One of the main reasons is that we have always had a special concern about offender patients dating right back to the middle of the 19th century. 
The high secure hospitals have gone through a variety of phases and they have been appallingly badly managed at times, but if you read the Surgeon of Crowthorne (Winchester, 1999) you will realise that at the end of the 19th century things weren't too bad at all. In my lifetime we have had phases of dreadful overcrowding, there has also been dreadful management at times, there has been a severe shortage of doctors, dreadful things have happened, but there have also been very good phases. The most recent good phase was when the government at last decided to do something which many of us had wanted them to do for a long time, to disconnect the hospitals from central government and have an overall, largely independent, authority which looked after them. The Special Hospitals Service Authority had a tremendous impact, including bringing the hospitals up to the standard required by the Mental Health Act Code of Practice. For example, seclusion at night was ended, but now the government is trying to bring it back! The Tilt Report is a disaster (Tilt et al, 2000). It will take a long time to recover from that, but given the history of the special hospitals from 1815 onwards I'm sure they will.

I wonder whether you think there has been a changing ethos in forensic psychiatry over your career, from being essentially about the care of offender patients to being about risk management? Do you see a danger of us losing our core values?

I think there's a danger of it but I'm not a pessimist about that. The National Health Service (NHS) itself, for all its faults and failings, represents a deep-rooted feeling in this country for caring for patients. I think we can preserve that. This faculty cannot do this alone; we've got to join with all the other faculties. As long as we can keep a core understanding of what we're about, we will not split off from mainstream medicine. It's important that we realise we are doctors and not lawyers, policemen or prison officers.

Do you not think we have much to learn from forensic psychiatry colleagues in the United States in relation to the rigorous training they have in legal issues?

I am unenthusiastic about the legal training of doctors. My simple view is that if we need legal advice, let's get it from someone who is a practising lawyer. If you sit in as I have done - on forensic psychiatry training sessions in centres in the United States, you find they don't learn much about patient care; what they get is seminars about the law. I'm not impressed that that's better than our training.

Another contentious topic is that of personality disorder. What are your views about the current debates in this area?

One couldn't but have some ambivalence about this issue given the draft Mental Health Bill which is driven by muddled notions about risk assessment and dangerous people running amok. My concern has been that we as psychiatrists were beginning to say we haven't got enough resources to go round so we're not going to deal with people with personality disorder, or we are going to focus on people with psychosis. That is valid up to a point, but what it did was to create a reaction among those who were left with such patients, particularly the probation service. They were saying they were being left with highly disordered people who are being dumped by psychiatrists. We would have done better to have got together with the probation service and jointly pointed out to the government the consequences of the shortage of these resources. I think we have to advocate systems that provide for all patients.

One thing you have been formidably good at is pushing issues through and facing battles of all sorts. How do you handle them and cope with the costs of them? Let's take the Fallon Inquiry into the Personality Disorder Services at Ashworth Hospital (Fallon et al, 1999) as an example.

There were lots of rows in the College, that's for sure. It was a grossly unfair report; it was picking on people. It was outrageous that people should be severely criticised without an opportunity to defend themselves and without any collegiate support. When I sat on the Royal Commission for Criminal Justice, inevitably the idea was floated that we should get rid of the adversarial system and replace it with an inquisitorial system. 'Inquisitions? Do you really want inquisitions?' said the chairman of our Commission. 'OK let's hear about inquisitions' and people started to bring evidence about the inquisitorial system from the continent, and convinced us all immediately to drop the idea. Now, all our public inquiries are inquisitions. If you decide someone is to blame for something and they have no opportunity to refute that, you can construct the evidence in your court towards that end; that's what inquisitions have always done. I don't think inquiries in public life are very useful anyway, but if we are going to have them let's have fair ones - let's have it so that both sides can put the arguments and argue them out in front of a neutral arbiter, the judge.

One of the other dangers of the Fallon report was that it could have led to the sweeping away of the highsecurity hospitals. We in this faculty all know how important those beds are to the whole of the NHS, but not everyone has that understanding.

When you look back, what achievements do you personally feel most pleased about?

The thing that gave me most day-to-day satisfaction was my out-patient clinic. Many times people would come to me and say 'Why don't you give up out-patients?' I'd say 'I'm a doctor, that's how I have to work, and without that I don't have a way into all the other things I am interested in.' I'll give you a little example of that. Two or three days after the Home Office document on DSPD (Home Office \& Department of Health, 1999) was published a patient came to me and said 'I've got to stop coming to see you'. So I said 'Why?'. He said 'Well, you will have to lock me 
up'. I said 'What you mean?' He said 'Well I'm a personality disorder aren't I?' I said 'I never use that term, I don't use that term in my clinic, it's not something I ever say to any patient'. He said 'No but your registrar told me that I'm a personality disorder, so I am a personality disorder, and under the new law you'll have to lock me up, so I better leave before they introduce that law'; and he stopped coming. I don't think any politician would have any inkling of the impact of a document like that, and I don't think I would have done if I hadn't been in clinical practice. Anyway I like the work. I wanted to be a doctor when I was little boy, and I've done that since.

\section{And on your desert island, what one book and luxury} would you take with you?

I can tell you what the luxury would be, that's easy. It would be a video player with an infinite supply of films. I love films. A book? I've always wanted to be able to say I would take the Koran instead of the Bible. I haven't read that. But if you are only allowed one book? I'd want to take my library which is very precious to me and quite large. Out of that I suppose I would take the complete works of Shakespeare. Even last week I found a new delight in a play that I don't know; there's so much that you keep on finding in Shakespeare.

\section{Declaration of interest}

None.

\section{References}

FALLON, P., BLUGLASS, R., EDWARDS,

$B$, et al (1999) Report of the

Committee of Inquiry into the

Personality Disorder Unit, Ashworth

Special Hospital. TSO (The Stationery Office)

GUNN, J. (1977) Epileptics in Prison Academic Press.

HOME OFFICE \& DEPARTMENT OF HEALTH (1999) Managing Dangerous People with Severe Personality

Disorder: Proposals for Policy

Development. Home Office.

*Adrian Grounds Senior Lecturer in Forensic Psychiatry, University of Cambridge, Institute of Criminology, Sidgwick Avenue, Cambridge CB3 9DT, email:ag113@cam.ac.uk, Harvey Gordon Consultant Forensic Psychiatrist, The Oxford Clinic, Littlemore Mental Health Centre, Oxford 